ISSN 1923-1237

Vol 4, Issue I

Copyright 2018

Toronto, $\mathrm{ON}$

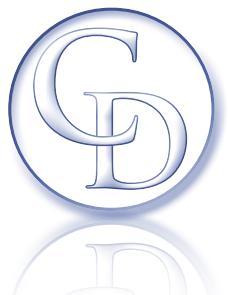

\title{
Toward a Critical Dietetics in the Nordic Countries
}

Nicklas Neuman, PhD and Elin Lövestam, PhD, RD

Uppsala University, Department of Food, Nutrition and Dietetics

\begin{abstract}
Whereas Critical Dietetics is still primarily centered in the Anglo-American countries, the movement is expanding internationally and has recently come to develop in the Nordic countries as well. On the 25th of August 2017, the first conference for Critical Dietetics in Scandinavia was held at Uppsala University, Sweden, and, following this, a network has been established: The Nordic Network for Critical Dietetics (NNCD). This paper is yet another step in this internationalization of Critical Dietetics. We discuss why we think that the Nordic countries have great potential to develop Critical Dietetics into an influential part of the future development of this promising international movement. We then explore three areas of controversy from a Nordic context that we see as touching upon, or being relevant for, Critical Dietetics. These are thematized as I) challenges to individualism and cognitivism in behavioral change policies, 2) working against body weight and "bad lifestyles" stigmatization, and 3) trust and recognition: challenges to the professions. Each area is illustrated by a few examples of Nordic research and current public debates and campaigns from Sweden. The main argument is that the Nordic region already has a soil in which seeds of Critical Dietetics have been sown; it is time for them to grow.
\end{abstract}

Introduction: the launch of a Nordic Critical Dietetics

On the 25th of August 2017, the first conference for Critical Dietetics in Scandinavia was held at Uppsala University, Sweden. Invited keynotes were John Coveney from Flinders University, Australia, and Catherine Morley from Acadia University, Canada, complemented with presentations from researchers from different countries, fields, and with different perspectives on eating. Following the evaluation of the one-day conference, an evaluation that indicated an optimism and ambition to move forward, a network was founded: The Nordic Network for Critical Dietetics (NNCD). The purpose of the name change from Scandinavian to Nordic was one of broader inclusion; Scandinavia consists of Sweden, Denmark, and Norway whereas the Nordic countries also include Finland, Iceland, and the Faroe Islands. The network has grown steadily, with just over 100 members after the first six months, although so far with an overwhelming majority of members from Sweden, most of them practitioners of the dietetic professions. The ambition, however, is a greater national diversity and inspiration from a variety of practice areas and academic disciplines. One additional step forward for a Nordic Critical Dietetics is this paper.

Our aim is to discuss three areas of controversy from a Nordic context that we see as touching upon, or being relevant for, Critical Dietetics. We see them as relevant because they all highlight issues related to dietetics that go beyond how and why people eat the way they do, and the effects of those eating habits on individual health. Instead, they stimulate critical investigations of systemic, ethical, political, and professional issues involved in dietetic research and practice. Each area is illustrated by a few examples of Nordic research and current public debates and campaigns from Sweden (for 
the simple reason that it is the national context we know most about). We will also discuss why we think that the Nordic countries have great potential to develop Critical Dietetics into an influential part of the future development of this promising international movement. We will however start with a discussion of what we mean by the term "critical," finished by some concluding remarks about Critical Dietetics in the Nordic countries.

\section{Defining "critical"}

To start with, what do we mean when we say that our approach to dietetics is critical? In answering this question, one way to start is, simply, by starting at the beginning, which brings us to Karl Marx. In one of a series of letters to Arnold Ruge (a German author) in September 1843, Marx argued that in his philosophical project:

"we do not confront the world in a doctrinaire way with a new principle: Here is the truth, kneel down before it! We develop new principles for the world out of the world's own principles. We do not say to the world: Cease your struggles, they are foolish; we will give you the true slogan of struggle. We merely show the world what it is really fighting for, and consciousness is something that it has to acquire, even if it does not want to" (Marx, [1843] n.d., emphasis in original).

As suggested in the quote, his philosophy did not entail the substitution of one unquestionable truth for a new unquestionable truth, nor is his philosophy a proposal to change slogans of struggle for new slogans of struggle. Marx offers a way to think in order to acquire an understanding of what there is to fight for. He finished the letter by formulating his philosophical purpose as "self-clarification (critical philosophy) to be gained by the present time of its struggles and desires" (Ibid.). The quote is rather obscure, but encapsulates an ambition to understand ourselves, who we are and why, through examinations of contemporary struggles and desires. In a clearer way, the same message was then postulated in his eleventh thesis on Feuerbach (Marx, [1845] 2002), a quote that is now engraved in the entryway of the Humboldt University in Berlin: "The philosophers have only interpreted the world, in various ways; the point is to change it." The quote must not be misinterpreted as a call to mindless action; that philosophical reasoning should be thrown out the window and substituted for non-reflective activism. Instead, Marx was seeking a philosophy rooted in history, a justification for emancipatory struggles based on the situatedness of what we take for granted as well as why we take it for granted. In his own line of thinking, this was the superstructure of a bourgeois ideology that had risen upon a base of economic relations (the means of production) known as the capitalist system.

The authors of this paper do not identify as Marxists, nor do we find it relevant to further discuss, or in any way oppose or support, his overall arguments about ideology, the political economy, and so forth. We do believe, however, that his principle of a critical philosophy holds as a starting-point for a Critical Dietetics as well. Therefore, the critical part of Critical Dietetics, as we see it, build on two principal assumptions.

Assumption 1: All that we believe to be true or that we take for granted could be wrong. This does not imply a total relativism of knowledge or morals, only a humble recognition of our values and knowledge as contextually produced.

This first assumption reflects a general agreement with the authors of the discussion paper (Gingras et al., 2014) and the declaration (Aphramor et al., 2009) of Critical Dietetics in that we recognize the nutritional and clinical sciences as cornerstones of dietetics, and we acknowledge the hard and important work of dietetic professions in the present and in the past. We would even go as far as stating that a respectful and reciprocally open-minded relationship with conventional dietetics and nutrition sciences is essential for Critical Dietetics. We are therefore strongly in favor of scientific standards and evidence-based practice of the dietetic professions, and we are in opposition toward dietetic promotions and practices based on pseudo-scientific claims that can hurt people. Still, Critical Dietetics must nevertheless practice reflexivity by questioning the fundamental assumptions and standpoints of dietetic and nutritional sciences and practices, illuminating their historicity and exposing how they come to be acknowledged as legitimate knowledge in particular contexts.

From this follows that justification of a given standard can only be argued for based on evidence and logic of argument. For example, let us apply the moralphilosophical framework of Rawls ([197I] 1999). Imagine that we were to be placed behind a veil of ignorance and faced with the question of which society we would prefer to walk into as the veil is removed, with our economic level, gender, sexuality, skin color, and so forth all being a total mystery. Most of us would probably choose a society that does not discriminate on the bases of gender or skin color, one that does not leave people 
to die if they cannot pay for healthcare, one that feeds the starving, and so on. Neither would we, probably, choose a society where people with non-conforming body size were forced to starve because the state has decided that this is in favor of the collective (behind the veil of ignorance you do not know if the force-starved person will be you), or where the "perfect diet," that one has no choice but to eat day in and day out, is decided from a totalitarian central planner. In short, that morals are relative does not mean that moral standpoints are arbitrary, and that knowledge is situated and historical does not mean that we are unable to create increasingly stronger models of reality.

Assumption 2: Critical Dietetics is normative in the sense that we (i) recognize and take responsibility for the fact that what we do as researchers and practitioners have social and political consequences, that we (ii) consider action toward social change as a central part of what we do, while we (iii) do not attempt to create a "once and for all" dogma about how to think, what to do, or what to prioritize.

The first point of this second assumption reflects the eleventh thesis on Feuerbach (Marx, [1845] 2002); the point is to change what we consider to be wrong, not only to explain it. The third point reflects his argument about avoiding truths to bow down in front, or proposing narrow dogmas of struggle. Thus, the normative aspect does not imply that all must share the same opinions about which directions of social change are the most important or desirable. Some members of Critical Dietetics might want to be activists, and we would not object to it, but it surely cannot be an expectation either. Critical Dietetics must be diverse, and disagreements and differences in perspectives should be encouraged albeit conveyed with mutual respect.

\section{Opportunities for Nordic Critical Dietetics}

Our experiences from the Scandinavian conference and the Nordic network is, thus far, that practitioners desire a forum to air questions about issues that they experience in their everyday practice, but that goes beyond the content of most dietetic conferences or meetings, or that which occurs in the basic academic training. Also, many researchers have a curiosity or a firm ambition to dig deeper into, and engage with, the social and human sciences in new ways. This is our point of departure for this section of the paper: the opportunities we already have in the Nordic countries for the establishment and positive development of Critical Dietetics.
The Nordic countries have a long history of public policies and "social engineering" with the aim of producing a healthy population. One example from Sweden was the "Report on the nutrition question" (Betänkande $i$ näringsfrågan) (Statens offentliga utredningar, 1938), in which the country's general nutrient standards and requirements were investigated by the state. Another early example of Swedish public health policies was a law in 1946 about municipalities having the right to be subsidized from the state in order serve lunches to all pupils. This was followed in 2011 by a sharpened law that school meals should also be nutritious. In 1989, the Key Hole symbol was introduced to use in the labeling of healthier options of different food categories. It is a package label guaranteeing that the nutritive value of the product adheres to certain nutritional criteria (fiber, wholegrain, salt, sugar, and composition of dietary fats) and therefore serves the purpose of guiding consumers (National Food Agency, 2015). This was established as an initiative from the National Food Agency (adopted in Denmark and Norway in 2009).

Moreover, whereas public dietary recommendations have a long history, the recent update of the Nordic Nutrition Recommendations went beyond nutrition for the first time, also acknowledging environmental issues (Nordic Council of Ministers, 2014). This might, at first glance, seem like a small step and a commonsense one given the global threat of climate change. But it is a quite large step when one thinks about the historically narrow nutritionism (Scrinis, 2013) in such policies. Another example of a public health initiative with a transnational Nordic focus was the New Nordic Diet; a diet regime with an ambition to be environmentally sustainable and as healthy as the Mediterranean Diet, but based on foods produced and grown in the Nordic region. This was a large project involving industry, politicians and leading researchers in nutrition and social science called OPUS, with a budget of DKK 100 million (approx. EUR 13,4 million and USD 16 million) (Leer, 2016).

The Nordic countries are generally seen as countries with high levels of trust in the government, in research, in the health care sector and in public agencies. Furthermore, the countries are shaped in a mostly social democratic political history with strong ideals of social equality, but also liberal in terms of gender, sexuality, and personal integrity. This Nordic model was historically constructed as a "middle way" of social and economic structure in which social equality was 
sought for through a distributive tax system and social policies while the countries reaped the benefits of the capitalist economy and the individual freedom of liberal democracies (Andersson, 2009; Andersson \& Hilson, 2009). This, of course, is a theoretical construction that is subject to criticism from all political sides, but regardless of the differences in opinions about the system, it is undoubtedly the case that it has shaped the region's modern history. As such, we believe that the Nordic countries share an ideological foundation as well as a societal and academic structure in which Critical Dietetics can develop. Moreover, and as we demonstrate in the next section using three areas of controversy in dietetics, there are also debates and research going on in the region suggesting a solid foundation for a Nordic Critical Dietetics to build upon. We thematize these areas as I) challenges to individualism and cognitivism in behavioral change policies, 2) working against body weight and "bad lifestyles" stigmatization, and 3) trust and recognition: challenges to the professions.

\section{Challenges to individualism and cognitivism in behavioral change policies}

One critical view of dietetics and public health nutrition that has been growing in the Nordic countries during the last decade is a sociological challenge to orthodox models of behavioral change. In this challenge, primarily the individualist and cognitivist assumptions are criticized, as well as the effectiveness of the policies that follow from them, namely policies about information, skills and individual responsibility. By individualist, we mean the assumption that the drivers of behavior primarily reside inside individuals themselves, rather than as the result of a complex web of social conventions, culture, infrastructure, and financial constraints. By cognitivist, then, we mean the assumption that behaviors derive primarily from thinking and deliberation, not from genetic dispositions, bodily signals (hunger, pain, cold, etc.), or simply through more or less automated and routinized activities based on limited or no deliberation.

For example, Halkier and Jensen (20II) have challenged the deficit model of behavioral change (the assumption that "bad" behavior is the effect of individual deficits) in a study about eating habits among Pakistani Danish women. Reasons articulated for not eating "healthy enough" concerned conflicts with the cultural repertoire of dishes and foods rather than lack of knowledge. Common Danish foods that claimed to have been recommended by dietitians - for example rye bread or mayonnaise-simply did not fit into their everyday life. In a similar way, Holm (2003) has argued against the blaming of consumers in Danish discourses of "food quality." Respondents referred to a great deal of different strategies in their everyday food consumption, and decisions seemed to be the result of a mixture of elements. Their concerns of food quality, she writes, "were based not only on a preoccupation with their own, or their families', health and well-being but on wider societal developments within agriculture, industry and food culture" (145).

In a more detailed theoretical critique, Gronow and Holm (2015) have targeted the commonly adapted model of behavioral change called Theory of Planned Behavior (TPB) (Ajzen, 1991). TPB is said to be overly focused on cognitive aspects of behavior, losing sight of a great variety of other important aspects of our everyday action and exaggerating the role of individual deliberation and intentions. Moreover, the elements of the model are argued to be relationships that are conceptually logical rather than empirical. In other words, they are so similar when operationalized that correlations have more to do with their conceptual similarities than by their actual explanations. Last but not least, given that TPB claims to be universal, it is quite contradictory that many researchers complement it and reconfigure it. That implies that it is, in fact, not universal at all.

Social cognitive models such as TPB have been criticized greatly for their questionable assumptions of human action and the lack of robust evidence in their favor (Ogden, 2003; Sniehotta, Presseau, and Araújo-Soares, 2014). Still, they seem to thrive in dietetic research and reproduce the idea that people behave in certain ways (e.g. how they eat or exercise) as an outcome of deliberate choice where costs are judged against benefits. This is not all wrong of course, but overly simplistic and not universal for all decision-making situations. Moreover, the reproduction of the idea that people eat the way they do because of factors of their individual cognition have implications for public policy and clinical practice. Interventions continue to be focused on information and marketing strategies, assuming that rational consumers will behave "correctly" when faced with enough convincing evidence. This has been tried for decades and it has not worked satisfactorily.

One Swedish example of a public health initiative that has moved beyond this orthodox understanding of behavioral change comes from a group of Swedish physicians and public health scientists. It is called 
"The Obesity Initiative" (Fetmainitiativet) (https:// fetmainitiativet.wordpress.com). In a public call to action, the initiators suggest five target areas to promote health:

I. Healthier options should be made easier, i.e., the standard selection rather than something one has to actively choose in an environment full of cheap and easily accessible foods that are less healthy. The initiators' suggestions have to do with fiscal policies and restrictions on advertising, especially advertising that targets children and adolescents.

2. Increased priorities on prevention in the health care sector.

3. An infrastructure that stimulates physical activity. This suggestion targets both schoolyards as well as cycle lanes.

4. Specific focus on children through healthy school meals, no exposure to unhealthy snacks in cafeterias, and access to physical activity in schools.

5. A fight against body weight discrimination and stigma In short, this is a call for politicians to focus more on the environment that surrounds individuals and less on blaming them for "failing." Note that there are no suggestions about information campaigns presented here, rather suggestions to counter messages from advertisers. The aim of the suggestions is thus for people to lead healthy lifestyles without deliberately choosing, or at least to make healthier habits simpler and unhealthier ones harder.

In sum, respected Nordic food researchers have been successful at criticizing individualist and cognitivist assumptions of behavioral change. "The Obesity Initiative" shares many of these social-theoretical ideas but without the theoretical terminology, and we have noticed that the same ideas are common among many practitioners of the dietetic professions as well. Amalgamating these two strands of theory and practice could be one continued target of a Nordic Critical Dietetics. This would result in new scientific questions asked, leading to both research and practice being designed in innovative ways. In the end, policy recommendations and treatments might change in a less individual-focused and less cognitivist direction, assuming that that they are accepted politically. And achieving political acceptance might be an even harder task.

\section{Working against body weight and "bad lifestyles" stigmatization}

Another question worthy of critical dietetic inquiry is body weight and "bad lifestyle" stigma. This issue is tightly connected to the previous section, given that basic assumptions about consumer choice that have been the social scientific orthodoxy in recent decades make it easier to blame individuals for their "failures." We mentioned "The Obesity Initiative" in the previous section, but that initiative is not exclusive in highlighting body weight stigmatization. For example, in 2016 a debate started among Swedish clinical dietitians regarding this issue. Some criticized the approach among established Swedish researchers and experts, arguing that it reflected a blaming and stereotyping health care approach that dietitians should work against (Magnusson \& Hedström, 2016; cf. Ramos Salas et al., 2017 for an international perspective). As a continuation of this debate, representatives from the Swedish Health at Every Size Organization (Hälsa Oberoende av Storlek, HOBS), were invited to share their experiences from health care in Dietistaktuellt, the Swedish Association of Clinical Dietitians' official magazine, and a discussion was initiated regarding how Swedish dietitians could engage against people and their habits (Vinglid, 2016).

Another example of this ongoing Swedish debate is the criticism of the Swedish Association of Clinical Dietitians' (Dietisternas riksförbund, DRF) annual Christmas campaign. In recent years, DRF have sent Christmas cards to politicians, organizations, and other societal stakeholders. The message is that people should change their dietary habits to decrease cancer risk, and the cards include advice such as "avoid sugar-rich drinks," "avoid salty food," and "try to maintain a healthy weight." In 2017, six Swedish dietitians criticized this initiative in a debate article, highlighting its judgmental tone and arguing that this kind of activity may hurt people through increasing the stigma of body weight and "bad lifestyles" (Eiben et al. 2017). They also argued that the approach might hurt the dietetic profession as it decreases peoples' trust in it.

Furthermore, Nordic researchers have questioned the medicalized understanding of "overweight and obesity." For example, Smith and Holm (2012) investigated the embodied experiences of fatness among Danish men and women with different levels of education. What they found was, among other things, that weight concerns were omnipresent for the highly-educated women who 
described it as threats to their careers and as shameful in their roles as mothers and wives. For the less educated women, however, the experiences of fatness were more associated with specific situations where they were reminded about it, such as when strangers commented on their weight or when they were shopping for clothes. For men, both the highly and less educated, "obesity" was described as more of a medical problem than anything else. While this study is small, 20 interviewees, and with only middle-aged participants, it opens up for hypotheses around "obesity" and socioeconomic status that, again, challenges the idea that people are fat because of a general deficit in knowledge. A similar argument can be put forth based on the result from a Finnish study about weight management as part of everyday practices (Jauho, Mäkelä, \& Niva, 2016). Weight management was described as competing with a plethora of everyday responsibilities and values and not necessarily being a matter of knowledge "deficits."

Although tightly connected to genetic dispositions, meaning that differences in body size can largely be explained by the inter-individual differentiation of genes, there seems to be a social regulation of the body that bears markers of class position resulting in socially differentiated ways of handling this issue. Moreover, managing one's weight is, for some people, a full-time job that competes with other concerns in everyday life. For a person who has drawn the winning ticket in the genetic lottery, weight management will never be a concern. But given that one is less lucky, managing one's weight is a struggle that might be just as hard even if one "knows better." This question, regarding stigmatization and victim-blaming of certain body shapes and habits, is arguably one of the most important questions for Critical Dietetics to consider.

\section{Trust and recognition: challenges to the professions}

Among the Nordic dietetic professions, we have observed similar endeavors for professional acknowledgement and recognition as those highlighted in Canada by Gingras (2009), such as struggles to become respected professions and to balance competing discourses of food and eating. This last section will focus on challenges for the dietetic professions in a time in which they have been subject to criticism about trustworthiness and having their professional judgments devalued. First of all, during the last decade, the Swedish dietetic professions have been put under pressure related to public debates about nutrition recommendations and "fad diets," the lion's share of debates taking part in social media. This has been particularly strong in relation to low carbohydrate high fat (LCHF) diets.

The debate builds on harsh criticism of the evidence for certain nutrition recommendations, especially the ones concerning carbohydrates and saturated fats, but also about misbeliefs in the trustworthiness and honesty of dietetic professions and the National Food Agency (Gunnarsson \& Elam, 2012; Neuman, 2015). A famous triathlon athlete and popular public voice in debates about food and health wrote a blog post entitled "Swedish dietitians should be ashamed! Take responsibility, now!" (Svenska dietister borde skämmas! Ta ansvar, nu!) (Colting, 2013). In short, clinical dietitians were claimed to be badly trained and self-indulgent "margarine Taliban who pray on their knees to the light milk god" (our translation) and who are unable to think beyond the guidelines of the National Food Agency that, apparently, form their education (a claim that is flatly wrong). The blog post is full of profanity, aggressiveness, and imperatives for the people to rise against this group of professionals who are doing nothing but harm peoples' health.

This is a good example of the acrimonious tone of the current debate on the trustworthiness of dietetic professionals in Sweden. The accusations are severe, and a threat to the recognition of the dietetic professions. We must defend ourselves against such attacks while remaining humble to the fact that we do not sit on timeless truths that we, as some sort of health missionaries, must transfer into the minds of the "ignorant lay public." As Lordly (2016) has similarly argued, the image of the dietitian as a trusted expert is permeating all dietetic knowledge systems, making up the rules for what is recognized as legitimate knowledge. We agree that the complex nature of dietetic knowledge must be celebrated and not constrained, why we do welcome a constructive debate about expertise and knowledge in dietetics. As dietetic professionals, we need to appreciate the limits of our understanding and abilities, while this must not, of course, prevent us from clearly rejecting and opposing pseudo-scientific advice and approaches (both within and outside the dietetic profession) that might hurt people. We must balance our roles as academically trained experts with an acknowledgement that in a democratic society we are not the only ones with the right to speak on dietetic matters, and nor should we be. 
Furthermore, a Finnish study analyzing internet discussions demonstrated that proponents of LCHF diets were not anti-science or ignorant (Jauho, 20l4). Rather, they based their arguments more on personal experience, on other sources of competence (such as specific LCHF sympathetic researchers and physicians), and, as in Sweden, a disbelief of professionals grounded in supposedly financial conflicts of interest and prestige (cf. Gunnarsson \& Elam, 2012). And as shown by the same Finnish research group, public debates about dietary fats in Finland have changed over time, with actors outside the leading health expertise taking part in the framing of the debates about health and culinary consumption (Jallinoja, Jauho, \& Mäkelä, 2016).

The problem for us is in no way to open academic debate, and we do not consider people who follow alternative diets to be a group of ignorant dupes who blindly follow gurus. Rather, the issues to investigate in Critical Dietetics are the causes of such deep mistrust about academically trained professions and guidelines issued by state actors. What is it about our contemporary cultural, social and political environment that stimulates such disbelief to rise and spread? The quoted triathlon athlete is but one example, but he is influential in the Swedish debate and is in no way alone (many of his claims in the blog are also "supported" by references to the leading Swedish LCHF blog). Neither are clinical dietitians and the National Food Agency the only ones who are targeted. Foodservice dietitians, a dietetic profession in Sweden without the license to provide nutritional treatment in the healthcare sector, also struggle increasingly with people having strong opinions about the food to be served in the public meal sector, especially to children. This has raised media debates that center on the limits of what the public sector can be expected to provide, economically and morally, for the individual (e.g. Abramowicz, 2017; Öhman, 2016).

The exemplified situations cannot be handled sufficiently by the dietetic professions alone, but needs a broader understanding that can be helped by social scientific insights. It might intuitively feel as if the best solution is more information about the nutritional sciences and dietetic clinical practices. However, this means that we would be faced with more burdens of inventing a wheel that is in fact already rolling since matters of de-professionalization and the "death of expertise" (Nichols, 2017) is, at least in the Global North, a much broader societal and cultural phenomenon. And the debates about food in the public meal sector centers around important ideological questions about the limits of welfare state services, about individuality versus collectivity and, again, prevailing ideas of distrust in expertise. A more profound alliance with academics possessing expertise in public governing, in organizations, in politics and so forth will provide valuable guidance for critical analyses. Lastly, a difficult balancing act for Critical Dietetics is to respond to these types of aggressive critiques, sometimes akin to conspiracy theories, without losing sight of important critical points about governmentality, the webs of power imbued in the symbolic and legal "right" to make legitimate truth claims, nutritionism, the medicalization of bodies, and so forth. Critical Dietetics is, in short, a way of reflecting and reason about academic and moral dilemmas surrounding what we do.

\section{Concluding remarks}

On an international scale, Critical Dietetics is growing as a movement and research area, but still with a primarily Anglo-American perspective. This rather restricted geographical perspective of contemporary Critical Dietetics primarily reflects the geographical locations of its founders and is in no way a result of intentional exclusion or protectionism. Nevertheless, it is unfortunate, and this paper is one part of an ambition to expand Critical Dietetics, geographically and culturally, thus continuing on the path of "collectively expanding the body of knowledge in dietetics and continuing the inclusive, scholarly, collective, and pluralistic development of the profession" (Aphramor et al., 2009, p. 2). More specifically, we see it as a point of departure for the establishment of Critical Dietetics in the Nordic countries. We acknowledge, however, that the Nordic countries also represent the rich and highly privileged part of the world and that the most problematic differentiation of research, in all sciences, is the division of the Global North and the Global South. In other words, we do not see ourselves as "victims" and we think that a crucial issue for the whole intellectual movement of Critical Dietetics is to expand beyond the Global North. Our Nordic perspective is, again, simply one part of a more profound ambition to expand the movement and develop its objectives.

Throughout the paper we have, first, suggested two principal assumptions for the term "critical," drawing on Marx. As mentioned, this has nothing to do with an explicit affiliation with Marxism as such; it is merely a way of applying what we see as a reasonable way of 
conceptualizing a critical intellectual approach. Other ways of conceptualizing it are of course welcome, as are diverse opinions about the focus of our academic and practical efforts. As we have shown in this paper, several contemporary public debates and studies in the Nordic countries are relevant for Critical Dietetics. Among other things, it is about challenges to the social scientific orthodoxy of behavioral change, about body weight stigmatization and derogatory notions of people's "bad lifestyles," and about the balance act of highlighting our professions and our scientifically trained expertise while remaining self-critical and reflexive of our own positions and the consequences of our actions. Furthermore, besides contemporary debates and research we argue that these countries have a structural and ideological foundation that opens up for the possibilities for Critical Dietetics to be established among dietetic practitioners and researchers. Put differently, the Nordic region already sown the seeds of Critical Dietetics: it is time for them to grow.

\section{References}

Abramowicz, N. (2017). Skolmatsalen är ingen à la carterestaurang. Expressen. Retrieved from https://www. expressen.se/ledare/naomi-abramowicz/skolmatsalen-aringen-a-la-carte-restaurang/

Ajzen, I. (1991). The theory of planned behavior. Organizational Behavior and Human Decision Processes, 50(2), 179-211. doi:http://dx.doi.org/l0.1016/0749-5978(91)90020-T

Andersson, J. (2009). Nordic nostalgia and Nordic light: the Swedish model as Utopia 1930-2007. Scandinavian Journal ofHistory, 34(3), 229-245. doi: I0.1080/03468750903।34699

Andersson, J., \& Hilson, M. (2009). Images of Sweden and the Nordic countries. Scandinavian Journal of History, 34(3), 219-228. doi:10.1080/03468750903134681

Aphramor, L., Asada, Y., Atkins, J., Berenbaum, S., Brady, J., Clarke, S., . . \& Yarker-Edgar, K. (2009). Critical dietetics: A declaration. Practice(48), I-2.

Colting, J. (2013). Svenska dietister borde skämmas! Ta ansvar, nu! Retrieved from https://coltingblogg.com/2013/02//3/ svenska-dietister-borde-skammas-ta-ansvar-nu/

Eiben, G., Haby, K., Hedström C., Linderoth E., LjungkronaFalk L., \& Magnusson M. (2017). Julkort från DRF - ett kontraproduktivt utskick. Dietistaktuellt 26(4), 48-50.

Gingras, J. (2009). Longing for recognition: The joys, complexities, and contradictions of practicing dietetics. York, UK: Raw Nerve Books

Gingras, J., Asada, Y., Fox, A., Coveney, J., Berenbaum, S., \& Aphramor, L. (2014). Critical dietetics: A discussion paper. Journal of Critical Dietetics, 2(I), 2-12.

Gronow, J., \& Holm, L. (2015). Explaining consumer choice:
A critique of the theory of planned behaviour. In P. Strandbakken \& J. Gronow (Eds.), The consumer in society (pp. 123-148). Oslo: Abstrakt forlag.

Gunnarsson, A., \& Elam, M. (2012). Food fight! The Swedish lowcarb/high fat (LCHF) movement and the turning of science popularisation against the scientists. Science as Culture, 21, 315-334. doi:DOI:10.1080/09505431.2011.632000

Halkier, B., \& Jensen, I. (20ll). Doing 'healthier' food in everyday life? A qualitative study of how Pakistani Danes handle nutritional communication. Critical Public Health, 2I (4), 47I-483. doi:I0.1080/0958I596.2011.594873

Holm, L. (2003). Blaming the consumer: On the free choice of consumers and the decline in food quality in Denmark. Critical Public Health, 13(2), 139-154. doi:|0.1080/0958|5903100009766|

Jallinoja, P., Jauho, M., \& Mäkelä, J. (2016). Newspaper debates on milk fats and vegetable oils in Finland, 1978-2013: An analysis of conflicts over risks, expertise, evidence and pleasure. Appetite, 105(Supplement C), 274-282. doi:https://doi.org/l0.1016/j.appet.2016.05.035

Jauho, M. (2014). The social construction of competence: Conceptions of science and expertise among proponents of the low-carbohydrate high-fat diet in Finland. Public Understanding of Science, 25(3), 332-345. doi:|0.1|77/09636625|4558|67

Jauho, M., Mäkelä, J., \& Niva, M. (2016). Demarcating social practices: The case of weight wanagement. Sociological Research Online, 21 (2), 5.

Leer, J. (2016). The rise and fall of the New Nordic Cuisine. Journal of Aesthetics \& Culture, 8. doi:10.3402/jac.v8.33494

Lordly, D. (2016). The trusted expert as an ideological code: The social organization of dietetic knowledge. Journal of Critical Dietetics, 3(I), 43-49.

Magnusson, M., \& Hedström C. (2016). Kan vi dietister göra mer för att motverka stigmatiseringen av fetma? Dietistaktuellt, 25(4), 54-56.

Marx, K. ([1843] n.d.). Letter from Marx to Arnold Ruge. Kreuznach, September 1843. Retrieved from https://www. marxists.org/archive/marx/works//843/letters/43_09.htm

Marx, K. ([1845] 2002). Theses on Feuerbach. Retrieved from https://www.marxists.org/archive/marx/works//845/ theses/theses.htm

National Food Agency. (2015). The Keyhole. Retrieved from https://www.livsmedelsverket.se/en/food-and-content/ labelling/nyckelhalet 
Neuman, N. (2015). Fett- och kolhydratdebatten: Intertextualitet och positionering $\mathrm{i}$ en deliberativ demokrati. In C. Fjellström (Ed.), Klagandets diskurs: Matforskare reflekterar (pp. 93-III). Uppsala: Acta Universitatis Upsaliensis.

Nichols, T. (2017). The death of expertise: The campaign against established knowledge and why it matters. New York, NY: Oxford University Press.

Nordic Council of Ministers. (2014). Nordic Nutrition Recommendations: Integrating nutrition and physical activity. Copenhagen: Nordic Council of Ministers.

Ogden, J. (2003). Some problems with social cognition models: A pragmatic and conceptual analysis. Health psychology: Official journal of the Division of Health Psychology, American Psychological Association, 22(4), 424-428. doi:10.1037/0278-6133.22.4.424

Öhman,U.(2016). Dyrareskolmatnäralltflerbarnäterspecialkost. P4 Västernorrland. Retrieved from http://sverigesradio.se/ sida/artikel.aspx?programid=| |0\&artikel $=65|48| \mid$

Ramos Salas, X., Alberga, A. S., Cameron, E., Estey, L., Forhan, M., Kirk, S. F. L., . . \& Sharma, A. M. (2017). Addressing weight bias and discrimination: moving beyond raising awareness to creating change. Obesity Reviews, I8(II), |323-1335. doi:|0.1||||/obr.12592

Rawls, J. ([197I] 1999). A theory of justice (Rev. ed.). Cambridge, MA: Belknap.

Scrinis, G. (2013). Nutritionism: The science and politics of dietary advice. New York: Columbia University Press.

Smith, L. H., \& Holm, L. (2012). Embodied experiences associated with obesity and the management of bodyweight: Gender and social differences. Journal of Food Research, I(4), 7-16. doi:I0.5539/jfr.vIn4p7

Sniehotta, F. F., Presseau, J., \& Araújo-Soares, V. (2014). Time to retire the theory of planned behaviour. Health Psychology Review, 8(1), I-7. doi:10.1080/17437199.2013.869710

Statens offentliga utredningar, (1938). Betänkande i näringsfrågan (1938:6). Stockholm: Socialdepartementet.

Vinglid, J. (20।6). Fördomar och skuldbeläggande i mötet med vården motverkar behandling. Dietistaktuellt, 25(6), 46-47.

\section{Author Biographies}

Nicklas Neuman, PhD, is a Postdoctoral researcher at the Department of Food, Nutrition and Dietetics, Uppsala University. His research interests can mostly be placed under the umbrella of "the Sociology of food and eating". The main interests are consumption and climate change, practice-based approaches to food policy, health and illness, the gendered division of domestic foodwork, and gastronationalism. He is originally trained as an administrative dietitian and was one of the three initiators of the first Scandinavian conference on Critical Dietetics in Uppsala, Sweden, August 2017.

Elin Lövestam, RD, PhD, is an Assistant Professor at the Department of Food, Nutrition and Dietetics, Uppsala University. Her research concerns the dietetic professional role with focus on the nutrition care process, person centered care, and the professional identity of the dietitian. She has an interest in the language and discourses of dietetics as well as in the medicalization of food and eating. She was also one of the initiators of the first Scandinavian conference on Critical Dietetics in Uppsala, Sweden, August 2017. 